\title{
Dating Gold Artifacts \\ Applications for Noble Gas Analyses of Gold
}

\author{
Otto Eugster \\ Physikalisches Institut, University of Bern, \\ Sidlerstrasse 5, 3012 Bern, Switzerland
}

\begin{abstract}
Native gold contains gases that were incorporated when gold crystallized or that were implanted into the crystal lattice as decay products of uranium, thorium, and potassium. These elements are present in gold as trace elements. The quantity of ${ }^{4} \mathrm{He}$ produced by $\mathrm{U}$ and $\mathrm{Th}$ decay depends on the time when gold crystallized and can, thus, be used for detecting mineral fakes and, perhaps, faked 'objets d'art'. Gold is also present in meteorites. In particular, meteorites, which represent rocks from the martian crust are of interest because magmatic activity and occurrence of liquid water in the past might have resulted in gold enrichment by hydrothermal fluids and water derived sedimentation. It is anticipated that gold deposits will eventually be detected on Mars.
\end{abstract}

Recent studies (1) have shown that native gold contains gases that were incorporated by two different processes: (a) production by the decay of radioactive elements that are present as trace elements in native gold (1), and (b) trapping of fluids and gases as the native metal grew $(1,2)$.

In process (a) ${ }^{4} \mathrm{He}$ originates from the decay of $U$ and $\mathrm{Th}$ (and the nuclides in the subsequent decay chains), ${ }^{40} \mathrm{Ar}$ from the decay of ${ }^{40} \mathrm{~K}$, and the heavy Xe isotopes from spontaneous fission of uranium. These gases are implanted into the crystal lattice of gold and are released only when gold is heated up to its melting point $\left(1064^{\circ} \mathrm{C}\right)$. The high retentivity for $\mathrm{He}, \mathrm{Ar}$, and Xe opens the possibility of directly dating the time when gold crystallized. In process (b) all volatiles that were present in the environment of the forming gold were trapped in fluid inclusions. These decrepitate when gold is heated in a Mo crucible by inductive or resistance heating up to a temperature of about $500^{\circ} \mathrm{C}$. The fluid inclusions contain $\mathrm{H}_{2} \mathrm{O}, \mathrm{CO}_{2}, \mathrm{CH}_{4}, \mathrm{~N}_{2}$, noble gases, and some minor species. The significance of this feature is the prospect of using gold and its fluid inclusions for the study of paleogas composition.

The mass spectrometric technique designed for analyses of lunar samples and meteorites was applied to numerous samples of native gold (1). In this paper I focus on two special aspects of these investigations: (a) detection of faked gold crystals and (b) the possible occurrence of gold deposits on Mars as indicated by the presence of gold as a trace element in meteorites whose origin is Mars and by the characteristics of the martian crust.

\section{DETECTING MINERAL FAKES}

Early in 1990 specimens of faked gold crystals purported to come from the Santa Elena gold mine in Venezuela have been appearing on the mineral market. Hofmann (3) showed that these nearly perfect octahedral gold specimens (Fig. 1a) are man made. They can be distinguished from natural crystals by their polycrystalline character that stands out plainly when the fake crystals are etched in aqua regia. Laue backscatter and X-ray diffraction patterns also demonstrate polycrystallinity.

These gold crystals were manufactured recently from processed gold (bullion or coins) and should be devoid of ${ }^{4} \mathrm{He}$ as the decay time for the trace elements $\mathrm{U}$ and $\mathrm{Th}$ is far too short for producing measurable quantities of ${ }^{4} \mathrm{He}$. The results of the mass spectrometric analyses of ${ }^{4} \mathrm{He}$ and $\mathrm{U}$ (Th contributes only about $20 \%$ of the total ${ }^{4} \mathrm{He}$ concentration) for two samples were compared with the results for two samples of genuine Santa Elena gold crystals (Fig. 1b). These samples were obtained from the collection of the Museum of Natural History in Bern (Dr. B. Hofmann). In fact, the analyses of the faked gold samples yielded a 300 times lower ${ }^{4} \mathrm{He}$ concentration 


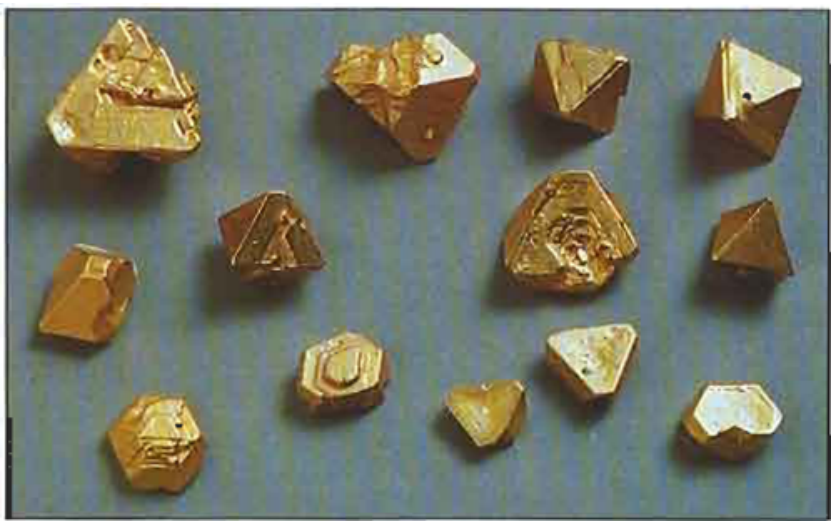

Figure 1a Faked octahedral gold crystals in the 1 to 30 gram range purported to come from the Santa Elena gold mine (Venezuela). Photo by P. Vollenweider.

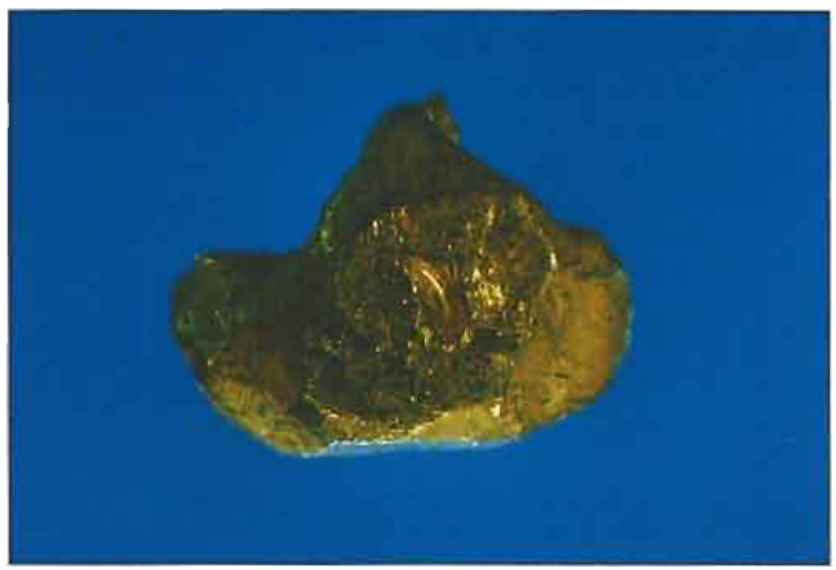

Figure $1 \mathrm{~b}$ Genuine gold crystal (length $3 \mathrm{~mm}$ ) from the Santa Elena gold mine. Photo by $M$. Zuber.

than the real Santa Elena samples (Table 1). The U concentrations of these samples are similar although the experimental uncertainty of the $U$ analyses are relatively large: after subtraction of a quite reproducible system blank of $0.20 \pm 0.02 \mathrm{ng} U$ the resulting concentrations have a $2 \sigma$-error of about $20 \%$ (Table 1). Ne and $\mathrm{Ar}$ are also depleted in the fake samples. In order to test the system blanks as realistically as possible, a sample of $306 \mathrm{mg}$ of commercially available gold wire (H. Jeanmaire S.A., Bienne, Switzerland, stock \# 505753, purity 99.99\%) was also analysed. The remaining amount of the noble gases in the fake gold and in the gold wire relative to the system blank without sample may be remnants of the gas originally present or traces of dissolved air trapped during the latest melting process. Since a few milligrams of gold are sufficient for an authenticity test based on ${ }^{4} \mathrm{He}$, this method can serve as an alternative method when other methods fail or have to be supplemented.

\section{Testing 'objets d'art' for authenticity}

Due to the low abundance of $\mathrm{He}$ in air and, consequently, the low He background of the analytical instruments and the high sensitivity of the mass spectrometer for He detection it is, in favourable cases, possible to verify the authenticity of 'objets d'art' manufactured from metals. Assuming a $U$ concentration of $0.03 \mathrm{ppm}$, a similar Th concentration, and an age of the object of 3000 years we expect $14 \times 10^{-12} \mathrm{~cm}^{3} S T P{ }^{4} \mathrm{He}$ per gram material (STP: atmospheric pressure and $0^{\circ} \mathrm{C}$ ). This concentration is about twice as high as the lowest system blank that may be achievable. We realize that it is out of question to precisely date such objects. However, we now plan to improve our analytical capability and to test whether

Table 1. Noble gas $\left(10^{-8} \mathrm{~cm}^{3} S T P / g\right)^{1)}$ and uranium $(p p m)$ concentrations in gold samples

$\begin{array}{llllll}\text { Sample } & \begin{array}{l}\text { Sample weight } \\ (\mathbf{m g})\end{array} & { }^{4} \mathrm{He} & { }^{20} \mathrm{Ne} & { }^{40} \mathrm{Ar} & \text { U } \\ \text { Santa Elena gold mine } & \begin{array}{l}30.1 / 20.4 \\ 20.6\end{array} & 62 & 0.02 & 29.8 & 0.0121 \pm 0.0020 \\ \text { "Santa Elena" fake } & 27.9 / 20.1 & 0.2 & 0.01 & 14.5 & \\ \text { Gold wire } 2) & 20.2 & & & & 0.0085 \pm 0.0017 \\ \text { System blank without sample } & 306.00 & <0.04 & <0.003 & 11 & \\ & \begin{array}{l}\left(10^{-8} \mathrm{~cm}^{3} \text { STP) }\right. \\ (\mathrm{ng})\end{array} & 0 & <0.0001 & 0.01 & 0.2 \pm 0.02\end{array}$

1) STP: atmospheric pressure and $0^{\circ} \mathrm{C}$. Experimental errors are about 5\%. The noble gas concentrations of the Santa Elena gold mine and the 'Santa Elena' fake samples are average values of two analyses.

2) See text. 
a difference in He concentration between fake objects and antique objects is detectable.

\section{GOLD ON MARS}

There is gold on Mars! The only questions are how much and whether it is concentrated in veins and ancient sedimentary deposits. There are three basic requirements for the formation of gold deposits in a planetary crust: (a) gold must be contained as a trace element in crustal rocks, (b) there must be magmatic activity, and (c) water must be present that circulates in cracks and that is essential for sorting cold in fluvial systems. We now discuss these requirements based on what is presently known about the martian crust and the processes that were active during martian history.

\section{Gold in the martian crust}

There is little doubt that some meteorites are rocks that were ejected as a result of asteroidal or cometary impacts on Mars and were captured by Earth. Until now, twelve meteorites, which in fact represent martian surface rocks, have been recovered on Earth. The mineralogical and chemical compositions of most of these meteorites were compared with those of martian surface material analysed by the two automated Viking landers in 1976 and 1977 (4) and close agreement in many respects was observed. The concentration of gold was too low to be directly measured in the Viking experiments. However, numerous chemical analyses including measurements of the Au concentration were performed for seven different martian meteorites (5). The concentrations of $\mathrm{Au}$ are between 0.3 and $21 \mathrm{ppb}$ with an average value of 3-4 ppb. For comparison, Au occurs in the Earth's crust in an average concentration of 3-5 ppb.

Are the twelve martian meteorites representative for the whole martian crust? There are two affirming arguments: first these meteorites belong to five different classes that differ in their major element chemistry indicating that they originate from different geologic provenance on Mars. Second, the times when these martian rocks were ejected from Mars could be derived based on the effects of exposure to cosmic rays on the meteoritic material during the travel from Mars to Earth: the conclusions of these studies are that six different events are responsible for the ejection of these twelve meteorites $-0.9,2.8,3.6,9.9,10.5$, and 15 $\mathrm{Ma}$ ago (6). It can be assumed that these six random asteroidal impacts occurred at six different sites on Mars.

\section{Magmatic activity on Mars}

The largest volcano in the solar system is Olympus Mons on Mars whose summit stands $26 \mathrm{~km}$ above the average altitude of the major plains. Global observations by the Mariner 9 orbiter (1971-1972) and the two Viking orbiter/lander missions showed that Mars resembles Earth with huge volcanoes, extensive lava plains, enormous canyons, and water cut channels (7). From crater count statistics and the crystallization ages of the martian meteorites (4) it can be concluded that the volcanic episodes must have spanned much of the decipherable martian history.

\section{Water on Mars}

There is no question that fluid water was once present on Mars. Estimates of the amount of water are based on large flood features, valley networks, and several other indicators. They suggest that an amount corresponding to a planet-wide layer of at least $500 \mathrm{~m}$ of water has outgassed from Mars (8). Channels provide the most obvious evidence for large amounts of water close to the surface. Immediately upon their discovery by the Mariner 9 spacecraft in 1972, the channels were recognized as probably having been formed by running water. The largest outflow channels are round the Chryse basin, where about $5 \times 10^{6} \mathrm{~km}^{3}$ have been eroded to form channels, chaotic terrain, and some of the smaller canyons. The occurrence of standing bodies of water have been tentatively identified in the area of Candor Chasma (9). As the surface temperature on Mars fell early in its history due

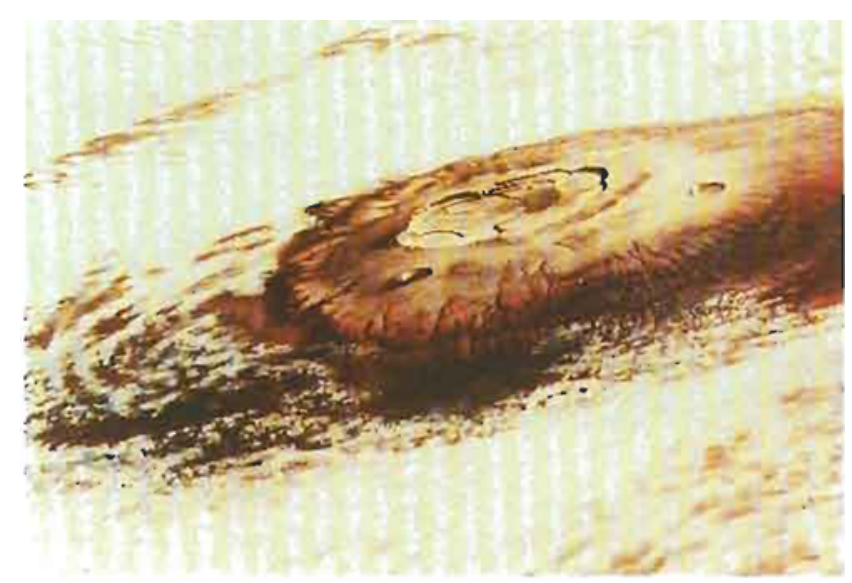

Figure 2 Clouds around Olympus Mons on Mars. This painting, based on a mosaic of black-and-white Viking orbiter images of Olympus Mons, shows the volcano's flanks and complex caldera protruding above thin clouds of water ice. (Painting by Gordon Legg, based on Viking Orbiter mosaic P17444. From NASA SP-444, 1980). 
to the fixation of atmospheric $\mathrm{CO}_{2}$ as carbonates and subsequent thinning of the atmosphere, a large fraction of the water is now present as ground water and ground ice well below the surface.

\section{CONCLUSIONS}

The investigation of the martian surface continues. The next missions will be Mars Lander 94 and Mars Pathfinder that will be placed on the surface of Mars in 1997. A manned Mars mission will probably follow in about 20 years and permanent installations will eventually be constructed. It is, thus, important to estimate the resources that are available directly from martian crustal material. As the requirements for gold enrichment are fulfilled - the martian crust containing gold in about the same concentration as the terrestrial crust, with past magmatic activity and past presence of rivers and water derived sediments - we can anticipate that gold deposits will be detected on Mars.

\section{ACKNOWLEDGEMENTS}

I thank Dr Beda Hofmann, of the Museum of Natural History of Bern, for the Santa Elena gold mine sample and the fake gold crystal, Dr. Robert Frei, of the University of Bern, for the $U$ analyses, and Dr. Pieter Meyer, of the Los Angeles County Museum of Art, for discussion. This work was supported by the Swiss National Science Foundation.

\section{ABOUT THE AUTHOR}

Dr Otto Eugster is Professor of Physics at the University of Bern. He has been involved for over 30 years in the analysis of the noble gases, other chemical elements and radionuclides in meteorites, lunar samples from the Apollo and Luna missions, and terrestrial samples. He is a Principal Investigator in the Lunar Sample Analysis Program of the National Aeronautics and Space Administration.

\section{REFERENCES}

1 O. Eugster, S. Niedermann, Ch. Thalmann, R. Frei, J. Kramers, U. Krähenbühl, Y.Z. Liu, B. Hofmann, R.H. Boer, W.U. Reimold and L. Bruno, J. Geophys. Res., 1995, 100, No. B12, 24,677

2 R.H. Boer, F.M. Meyer, L.J. Robb, J.R. Graney, T.W. Wennemann and S.E. Kesler, Economic Geology, 1995, 90, 860

3 B. Hofmann, The Mineralogical Record, 1992, 23, 283.

4 H.Y.Jr. McSween, Geology, 1984, 12, 3

5 A.H. Treiman, M.J. Drake, M.-J. Janssens, R. Wolf and M. Ebihara, Geochim. Cosmochim. Acta, 1986, 50, 1071

6 O. Eugster, A. Weigel and E. Polnau, 'Lunar Planet. Sci. XXVII', Lun. Planet. Inst., Houston, 1996, p. 345

7 M.H. Carr, 'The Surface of Mars', Yale University Press, p. 232, 1981

8 M.H. Carr, Nature, 1987, 326, 30

9 J.L. Gooding, M.H. Carr, C.P. McKay, EOS, $1989,70,745$ 